\title{
Cardiovascular effects of Hyptis fruticosa essential oil in rats
}

\author{
M.R.V. Santos ${ }^{\text {a,* }}$, A.A. Carvalho ${ }^{\text {a }}$, I.A. Medeiros ${ }^{\text {b }}$, P.B. Alves ${ }^{c}$, \\ M. Marchioro ${ }^{\text {a }}$, A.R. Antoniolli ${ }^{\text {a }}$ \\ a Laboratório de Farmacologia Cardiovascular, Universidade Federal de Sergipe, Av. Marechal Rondon, \\ S/N, Rosa Elze, CEP: 49100-000, São Cristóvão, SE, Brazil \\ ${ }^{\mathrm{b}}$ Laboratório de Tecnologia Farmacêutica, Universidade Federal da Paraíba, João Pessoa, PB, Brazil \\ ${ }^{\mathrm{c}}$ Departamento de Química, Universidade Federal de Sergipe, São Cristóvão, SE, Brazil \\ Received 8 November 2005; accepted 17 November 2006 \\ Available online 6 February 2007
}

\begin{abstract}
In non-anesthetized normotensive rats, Hyptis fruticosa essential oil (HFEO, 5, 10, 20 and $40 \mathrm{mg} / \mathrm{kg}$; i.v.) induced hypotension associated with tachycardia. In intact and isolated rings of rat superior mesenteric artery (control), HFEO $(1-1000 \mu \mathrm{g} / \mathrm{ml}, n=6$, cumulatively) induced concentration-dependent relaxations of tonus induced by $10 \mu \mathrm{M}$ phenylephrine $(\mathrm{Phe})\left(\mathrm{pD} \mathrm{P}_{2}=2.6 \pm 0.27\right.$; $E_{\max }=64 \pm 8.3 \%$ ). In denuded endothelium pre-contracted rings with Phe or $\mathrm{K}^{+}$-depolarizing solution $(80 \mathrm{mM})$, the concentrationresponse curves to HFEO were not shifted $\left(\mathrm{pD}_{2}=2.3 \pm 0.25\right.$ and $2.3 \pm 0.28$, respectively), but their maximal responses were significantly $\left(P<0.05\right.$ vs control) increased $\left(E_{\max }=122.3 \pm 18.2 \%\right.$ and $92 \pm 3.6 \%$, respectively). HFEO was also capable of antagonizing the concentration-response curves to $\mathrm{CaCl}_{2}(3 \mu \mathrm{M}-30 \mathrm{mM})$ in a dose-dependent manner.
\end{abstract}

(C) 2007 Elsevier B.V. All rights reserved.

Keywords: Hyptis fruticosa; Essential oil; Cardiovascular effects

\section{Introduction}

The use of medicinal plants for the treatment of human diseases has increased considerably worldwide. Evaluation of the effects of these plants on organs and systems contributes to the development of the scientific basis for their therapeutic application, and also enriches considerably the therapeutic arsenal for the treatment of a number of diseases $[1]$.

Hyptis has ca. 400 species distributed mainly at the central states of Brazil [2]. Various species are used in folk medicine as antiinflammatory, antinociceptive, anticonvulsant and antiulcerogenic [3-6].

Hyptis fruticosa popularly known as "alecrim do campo" or "alecrim do vaqueiro" is an aromatic sub-bush plant which grows up to $1.5 \mathrm{~m}$ found on the Brazilian northeast coast. Previous studies have demonstrated that the aqueous extract, the ethanolic extract, and the essential oil from $H$. fruticosa presented analgesic and anticonvulsive activities.

Considering that there are no pharmacological studies relating the effects of $H$. fruticosa to the cardiovascular system, this work aimed to evaluate the cardiovascular effects of HFEO in rats using in vivo and in vitro studies.

\footnotetext{
* Corresponding author. Tel.: +55 79 32126645; fax: +55 7932126474 .
}

E-mail address: marcio@infonet.com.br (M.R.V. Santos). 


\section{Experimental}

\subsection{General}

The drugs used were: sodium thiopental (CRISTÁLIA), heparin sodium salt (ARISTON), acetylcholine chloride (Ach), L-phenylephrine chloride (Phe) and cremophor (a derivative of castor oil and ethylene oxide used to emulsify water-insoluble substances) (SIGMA). All compounds were freely dissolved in distilled water (for in vitro experiments) or saline (for in vivo experiments).

\subsection{Plant}

H. fruticosa Salzm., ex Benth (Lamiaceae), collected near São Cristóvão, Brazilian State of Sergipe was identified by Prof. Dr. A. S. Ribeiro, Botanist in the Biology Department, Universidade Federal de Sergipe. A voucher specimen was deposited in the Herbarium of the Biology Departament, Universidade Federal de Sergipe. Code 007912.

\subsection{Extraction}

The HFEO was obtained from fresh leaves by steam distillation and stored at $4{ }^{\circ} \mathrm{C}$. Oil was dissolved in a saline/ cremophor $(0.1 \% \mathrm{v} / \mathrm{v})$ solution for in vivo experiments and in water distilled/cremophor $(0.1 \% \mathrm{v} / \mathrm{v})$ solution for in vitro experiments. Cremophor had no effect when tested in control condition (data not shown).

\subsection{Animals}

Male Wistar rats (200-350 g) were used for all experiments. Animals were housed under standard environmental conditions, fed with rodent diet and tap water ad libitum.

\subsection{Solutions}

The composition of the normal Tyrode's solution used was: $\mathrm{NaCl} 158.3, \mathrm{KCl} 4.0, \mathrm{CaCl}_{2} \cdot 2 \mathrm{H}_{2} \mathrm{O} 2.0, \mathrm{NaHCO}_{3} 10.0$, $\mathrm{C}_{6} \mathrm{H}_{12} \mathrm{O}_{6} 5.6, \mathrm{MgCl}_{2} \cdot 6 \mathrm{H}_{2} \mathrm{O} 1.05$ and $\mathrm{NaH}_{2} \mathrm{PO}_{4} \cdot \mathrm{H}_{2} \mathrm{O} 0.42 \mathrm{mM}$. $\mathrm{K}^{+}$-depolarizing solutions $(\mathrm{KCl} 60 \mathrm{mM}$ and $\mathrm{KCl}$ $80 \mathrm{mM}$ ) were done by replacing 60 or $80 \mathrm{mM} \mathrm{KCl}$ in the Tyrode's solution with equimolar $\mathrm{NaCl}$, respectively. In the nominally without $\mathrm{Ca}^{2+}$ solution, $\mathrm{CaCl}_{2}$ was omitted.

\subsection{Measurement of mean arterial pressure and heart rate in non-anesthetized normotensive rats}

For measurement of mean arterial pressure (MAP) and heart rate (HR), rats were anesthetized with sodium thiopental $(45 \mathrm{mg} / \mathrm{kg}$, i.p.). A polyethylene catheter was inserted into the abdominal aorta via the left femoral artery for pressure recordings. Another catheter was inserted into the lower vena cava via the left femoral vein for the administration of drugs. Both catheters were filled with heparinized saline and led under the skin to exit between the scapulae. After $24 \mathrm{~h}$ of surgery, rats were placed in large individual cages and experiments were performed in non-anesthetized rats.

The arterial catheter was connected to a pre-calibrated pressure transducer (Edwards Lifescience, Irvine, CA, USA) and pressure outputs were recorded in an amplifier-recorder (BioData, Model BD-01, PB, Brazil) connected to a personal computer equipped with an analog-to-digital converter board (BioData, PB, Brazil). For each cardiac cycle, the computer calculated the MAP, and pulse interval (referred to as heart rate).

After cardiovascular parameters had stabilized, MAP and HR were recorded before (baseline values) and after i.v. administration of randomized doses of HFEO $(5,10,20$ and $40 \mathrm{mg} / \mathrm{kg})$. Successive injections were separated by a time interval sufficient to allow full recovery of cardiovascular parameters.

\subsection{Preparation of isolated rat superior mesenteric artery rings}

Rats were killed by stunning and exsanguination. The superior mesenteric artery was removed, cleaned from connective tissue and fat and sectioned in rings (1-2 mm), which were suspended in organ baths containing $10 \mathrm{ml}$ of 
Tyrode's solution, gassed with a mixture of $95 \% \mathrm{O}_{2}$ and $5 \% \mathrm{CO}_{2}$ and maintained at $37{ }^{\circ} \mathrm{C}$. Isometric tension was recorded under a resting tension of $0.75 \mathrm{~g}$. During the stabilization period the solution was changed every $15 \mathrm{~min}$ [7]. The isometric tension was recorded through a force transducer (Gould, Model GM2, USA) coupled to an amplifierrecorder (Gould, USA). Endothelium was removed by gently rubbing the intimal surface of the vessels. The presence of functional endothelium was assessed by the ability of acetylcholine (ACh) $(10 \mu \mathrm{M})$ to induce more than $70 \%$ relaxation of pre-contracted vessels with phenylephrine $(10 \mu \mathrm{M})$. The absence of the relaxation to ACh was taken as evidence that the vessel segments were functionally denuded of endothelium.

\subsubsection{HFEO effect on phenylephrine $(10 \mu M)$ induced tonus in isolated rat superior mesenteric artery rings with or} without endothelium

After the stabilization period, two successive contractions of similar magnitude were induced with $10 \mu \mathrm{M}$ Phe in rings with or without endothelium. During the tonic phase of the third contraction, different concentrations of HFEO ( 1 , $3,10,30,100,300$ and $1000 \mu \mathrm{g} / \mathrm{ml}$ ) were added cumulatively to the organ bath. The relaxations were measured by comparing the developed tension before and after the addition of HFEO and expressed as percentage of relaxation from induced tonus.

\subsubsection{Effect of $H F E O$ on contraction induced by $\mathrm{KCl}$ in rings without endothelium}

After the stabilization period, rings without endothelium were pre-contracted with $\mathrm{K}^{+}$-depolarizing solutions $(\mathrm{KCl}$ $80 \mathrm{mM})$ and, on the tonic phase, different concentrations of $\operatorname{HFEO}(1,3,10,30,100,300$ and $1000 \mu \mathrm{g} / \mathrm{ml})$ were added cumulatively to the organ bath. The relaxations were measured as previously described.

\subsubsection{Effect of HFEO on concentration-response curves to $\mathrm{CaCl}_{2}$ in rings without endothelium}

After the stabilization period, the rings without endothelium were contracted with $\mathrm{K}^{+}$-depolarizing solution $(\mathrm{KCl}$ $60 \mathrm{mM}$ ) and washed with normal Tyrode's solution until full recovery of initial tension. After this, they were incubated with nominally without $\mathrm{Ca}^{2+}$ solution for 15 min and afterwards exposed to nominally without $\mathrm{Ca}^{2+}$ solution with $\mathrm{KCl}$ of $60 \mathrm{mM}$ for another $15 \mathrm{~min}$ [8]. Then, a first cumulative concentration-response curve to $\mathrm{CaCl}_{2}\left(3 \times 10^{-6}, 10^{-5}\right.$, $3 \times 10^{-5}, 10^{-4}, 3 \times 10^{-4}, 10^{-3}, 3 \times 10^{-3}, 10^{-2}$ and $\left.3 \times 10^{-2} \mathrm{M}\right)$ was obtained. In these same preparations, $\operatorname{HFEO}(0.3,3$,
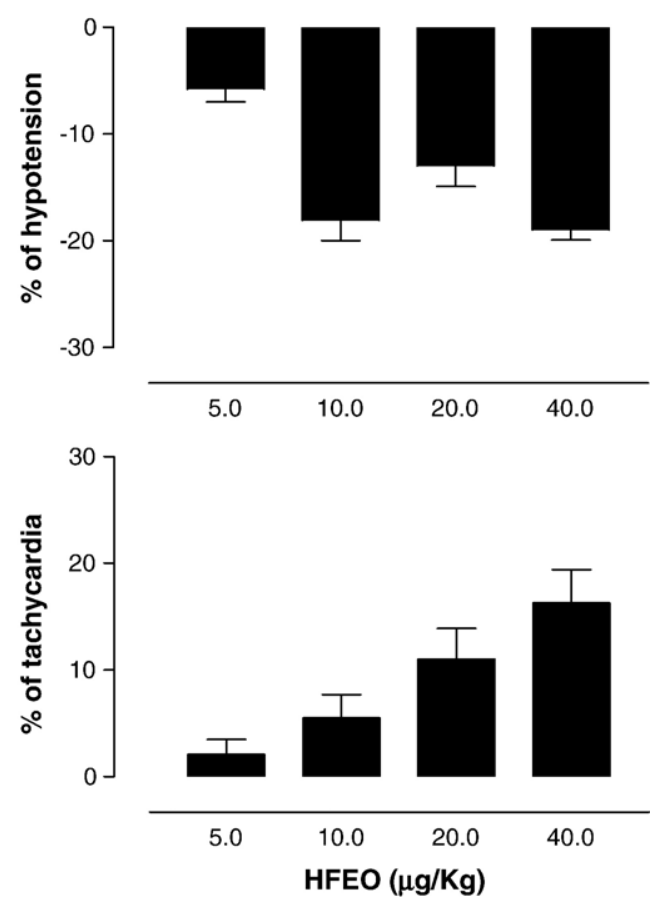

Fig. 1. Effect of $\operatorname{HFEO}(5,10,20$ and $40 \mathrm{mg} / \mathrm{kg}$; i.v.) on blood pressure and heart rate in non-anesthetized normotensive rats. Values are expressed as mean \pm SEM of six experiments. 


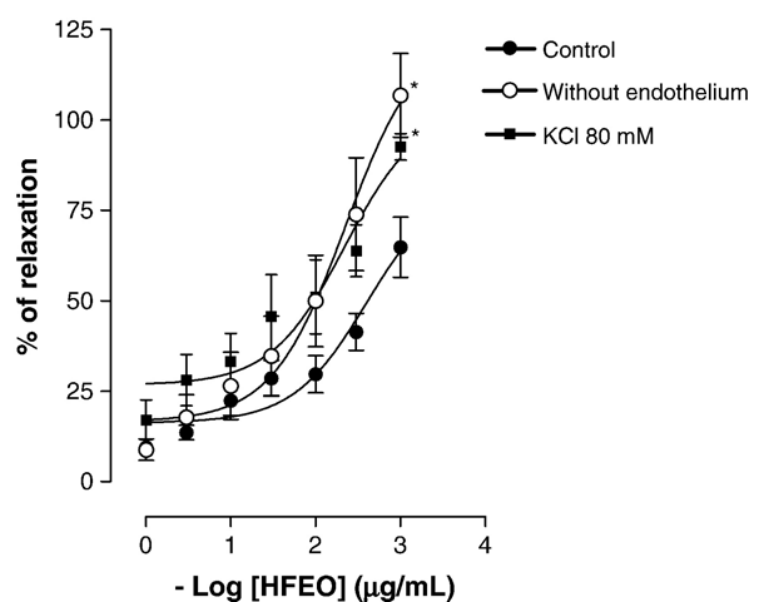

Fig. 2. Concentration-response curves to $\operatorname{HFEO}(1,3,10,30,100,300$ and $1000 \mu \mathrm{g} / \mathrm{ml})$ in rat superior mesenteric artery rings pre-contracted with $10 \mu \mathrm{M}$ Phe in the condition intact (Control) or after removal of endothelium (Without endothelium), and rings without endothelium pre-contracted with $\mathrm{K}^{+}$-depolarizing solutions $(\mathrm{KCl} 80 \mathrm{mM})$. Values are expressed as mean \pm SEM. $N=6$. ${ }^{*} P<0.05$ vs control.

30 and $300 \mu \mathrm{g} / \mathrm{ml}$ ) was individually pre-incubated for $15 \mathrm{~min}$ and a second cumulative concentration-response curve to $\mathrm{CaCl}_{2}$ was obtained. This curve was compared with that obtained in the absence of HFEO and the results were expressed as percentages of the maximal response to $\mathrm{CaCl}_{2}$ alone.

\subsection{Statistical analysis}

Values were expressed as the mean \pm SEM. When appropriate, Student's $t$-test or one-way ANOVA was done to evaluate the significance of the differences between means. The $\mathrm{EC}_{50}$ values were obtained by non-linear regressions of concentration-response curves and $\mathrm{pD}_{2}$ values were calculated through the negative logarithm of the $\mathrm{EC}_{50}$. All these procedures were done by using Graph Pad Prism ${ }^{\text {TM }}$ version 3.02 software.

\section{Results}

In non-anaesthetized normotensive rats, baseline MAP and HR values were $110 \pm 2 \mathrm{~mm} \mathrm{Hg}$ and $329 \pm 6 \mathrm{bpm}$, respectively. In these animals, the intravenous bolus injections of $\operatorname{HFEO}(5,10,20$ and $40 \mathrm{mg} / \mathrm{kg})$ induced a transitory

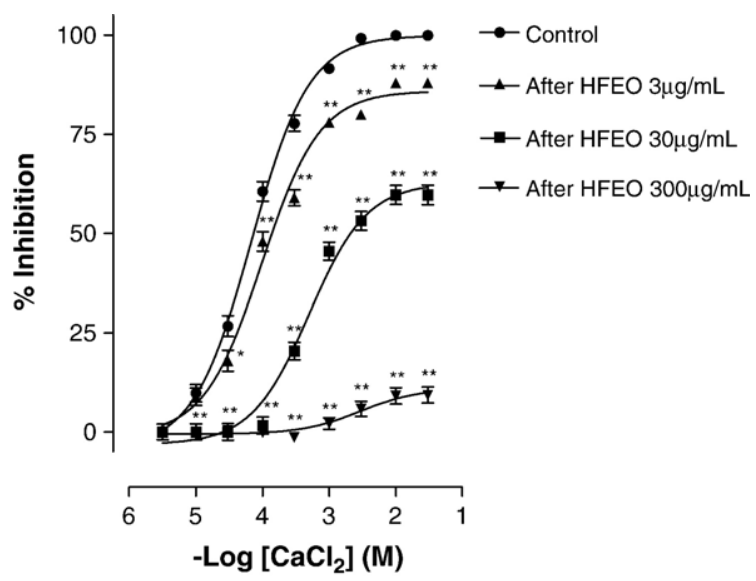

Fig. 3. Concentration-response curves to $\mathrm{CaCl}_{2}\left(3 \times 10^{-6}, 10^{-5}, 3 \times 10^{-5}, 10^{-4}, 3 \times 10^{-4}, 10^{-3}, 3 \times 10^{-3}, 10^{-2}\right.$ and $\left.3 \times 10^{-2} \mathrm{M}\right)$ in rat superior mesenteric artery without endothelium before (control) and after pre-incubation with HFEO at concentrations of $3,30 \mathrm{and} 300 \mu \mathrm{g} / \mathrm{ml}$, separately. Values are expressed as mean $\pm \mathrm{SEM}, N=6 .{ }^{*} P<0.05$ and ${ }^{* *} P<0.01$ vs control. 
reduction of blood pressure from 6 to $19 \%$ associated with an increase in heart rate from 2 to $16 \%$ (Fig. 1). The effects to each dose were fully recovered after $30 \mathrm{~s}$ (data not shown).

In intact isolated superior mesenteric artery rings of rats, $\operatorname{HFEO}(1,3,10,30,100,300$ and $1000 \mu \mathrm{g} / \mathrm{ml}$, cumulatively) induced concentration-dependent relaxations of tonus induced by $10 \mu \mathrm{M}$ phenylephrine $\left(\mathrm{pD}_{2}=2.6 \pm\right.$ $\left.0.27 ; E_{\max }=64 \pm 8.3 \%\right)$. In rings without endothelium pre-contracted with Phe or $\mathrm{K}^{+}$-depolarizing solution $(\mathrm{KCl}$ $80 \mathrm{mM})$, the concentration-response curves to HFEO were not significantly shifted $\left(\mathrm{pD}_{2}=2.3 \pm 0.25\right.$ and $2.3 \pm 0.28$, respectively), but their maximal responses were significantly increased ( $E_{\max }=122.3 \pm 18.2 \%$ and $92 \pm 3.6 \%$, respectively, $P<0.01$ ) (Fig. 2).

As showed in Fig. 3, $\mathrm{CaCl}_{2}\left(3 \times 10^{-6}, 10^{-5}, 3 \times 10^{-5}, 10^{-4}, 3 \times 10^{-4}, 10^{-3}, 3 \times 10^{-3}, 10^{-2}\right.$ and $\left.3 \times 10^{-2} \mathrm{M}\right)$ induced contractions in denuded rat mesenteric artery rings in a dose-dependent manner that were strongly inhibited after incubation with HFEO in doses of 3,30 and $300 \mu \mathrm{g} / \mathrm{ml}\left(E_{\max }=12 \pm 2 ; 41 \pm 2.4\right.$ and $81 \pm 2 \%$, respectively).

\section{Discussion}

In this work, we chose to evaluate the effects of HFEO on the blood pressure and heart rate in non-anesthetized rats in order to avoid anesthesia and surgical stress influences $[9,10]$. Baseline MAP and HR values were in agreement to those previously reported in other studies [11-14]. In these animals, acute intravenous administration of HFEO induced hypotension associated with tachycardia.

The control of blood pressure is mainly maintained by peripheral vascular resistance and the major contributor is the vascular tone of several arterial beds [15], so is the mesenteric bed [16]. In order to verify if the hypotensive response could be induced by the decrease in the peripheral vascular resistance due to a possible vasorelaxation, we performed in vitro experiments using rings from the isolated rat superior mesenteric artery. In these preparations, HFEO induced vasorelaxation in a concentration-dependent manner of Phe-induced tonus, suggesting that the hypotensive response induced by HFEO may be due to a direct action on the peripheral vascular resistance. These initial results are in agreement with those of other studies that had demonstrated that several essential oils present a potent hypotensive effect through a direct vasorelaxant effect $[13,14,17-19]$. Furthermore, HFEO contains $\alpha$-pinene and caryophyllene, substances with potent smooth muscle relaxant activity [20,21], and 1,8 cineole, with hypotensive activity [11]. Then, it is possible to hypothesize that the effects induced by HFEO could be due to the presence of these compounds. However, further experiments are necessary to clearly elucidate this assumption.

It is well known that the endothelium is an important regulator of the vascular tone by releasing endotheliumderived relaxing factors [22], mainly $\mathrm{NO}$ and COX-derived products, such as $\mathrm{PGI}_{2}[22,23]$. In order to investigate the participation of the endothelium in the vasorelaxant response induced by HFEO, we performed experiments in the absence of functional endothelium. In these conditions, the vasorelaxant response induced by HFEO was increased. This suggests that the presence of endothelium is not essential for relaxant response expressions and that an endothelium-independent pathway is probably implicated in this effect.

Calcium is the primary regulator of tension in vascular smooth muscle [24]. It is well known that the maintenance of smooth muscle contraction depends on $\mathrm{Ca}^{2+}$ influx from extracellular space through voltage and/or receptor operated calcium channels (VOCCs and/or ROCCs, respectively) [25]. It is well reported that the increase in external $\mathrm{K}^{+}$concentration $(\mathrm{KCl} 80 \mathrm{mM})$ induces smooth muscle contraction through VOCCs activation and subsequent calcium release from the sarcoplasmic reticulum [25]. The high $\mathrm{K}^{+}$-induced contraction is inhibited by $\mathrm{Ca}^{2+}$ channel blockers or by removal of external $\mathrm{Ca}^{2+}$ and is, therefore, entirely dependent on $\mathrm{Ca}^{2+}$ influx [25]. Thus, we evaluated the HFEO effect on intact rings pre-contracted with $\mathrm{K}^{+}$-depolarizing solutions $(\mathrm{KCl} 80 \mathrm{mM})$. This set of experiments revealed that HFEO-induced vasorelaxations, which were more efficacious in this experimental condition than in those in rings pre-contracted with Phe, suggest that HFEO appears to inhibit $\mathrm{Ca}^{2+}$ influx through VOCCs.

In order to check the hypothesis above, we constructed a concentration-response curve to $\mathrm{CaCl}_{2}$ in high $\mathrm{K}^{+}$solution before and after incubation with HFEO. In these conditions, HFEO was capable of antagonizing the $\mathrm{CaCl}_{2}$-induced contractions in a concentration-dependent manner. As reported by Chan et al. in Ref. [26] nifedipine, a L-type voltageoperated $\mathrm{Ca}^{2+}$ channel blocker, also inhibited the concentration-response curve to $\mathrm{CaCl}_{2}$, suggesting strongly that HFEO could be acting possibly as a calcium channel blocker.

In conclusion, the results obtained in this work showed that HFEO induces hypotensive effect with a contemporaneous increase in heart rate probably of reflex origin. This hypotensive effect may probably be due to a 
direct vasodilatation and a consequent decrease in the peripheral vascular resistance. This vasodilatation seems to be due to an inhibition of the $\mathrm{Ca}^{2+}$ influx through voltage-operated $\mathrm{Ca}^{2+}$ channels.

\section{Acknowledgements}

We thank Prof. Dr. José M. Barbosa Filho for NAPRALERT search. This work was supported by grants from CAPES and FAP-SE, Brazil.

\section{References}

[1] Elizabetsky E. J Ethnobiol 1986;6:121.

[2] Harley RM. Bot J Linn Soc 1988;98:87.

[3] Barbosa PPP, Ramos CP. Phytotherapy 1992;6:114.

[4] Akah PA, Nwambie AI. Fitoterapia 1993;64:42.

[5] Kuhnt M, Probstle A, Rimpler H, Bauer R, Heinrich M. Planta Med 1995;63:227.

[6] Bispo MD, Mourão RHV, Franzotti EM, Bomfim KBR, Arrigoni-Blank MF, Moreno MPN, et al. J Ethnopharmacol 2001;76:81.

[7] Altura BM, Altura BT. Am J Physiol 1970;219:1698.

[8] Goodfraind T, Miller R, Wibo M. Pharmacol Rev 1986;38:321.

[9] Smith TL, Hutchins PM. Am J Physiol 1980;238:H539.

[10] Fluckiger JP, Sonnay M, Boillat N, Atkinson J. Eur J Pharmacol 1985;109:105.

[11] Lahlou S, Figueiredo AF, Magalhaes PJ, Leal-Cardoso JH. J Physiol Pharmacol 2002;80:1125.

[12] Silveira AL, Gomes MAS, Silva Filho RN, Santos MRV, Medeiros IA, Barbosa-Filho JM. Rev Bras Farmacogn 2003;13:37.

[13] Cunha RM, Farias SRQ, Duarte JC, Santos MRV, Ribeiro EAN, Medeiros IA. Biol Geral Exp 2004;5:12.

[14] Guedes DN, Silva DF, Barbosa-Filho JM, Medeiros IA. Phytomedicine 2004;11:490.

[15] White RM, Rivera CO, Davison CB. Hypertension 1996;27:1245.

[16] Mulvany MJ, Aalkjaer C. Physiol Res 1990;70:921.

[17] Lahlou S, Leal-Cardoso JH, Magalhaes PJ. Planta Med 2000;66:138.

[18] Lahlou S, Carneiro-Leao RF, Leal-Cardoso JH, Toscano CF. Planta Med 2001;67:638.

[19] Lahlou S, Interaminense LF, Leal-Cardoso JH, Morais SM, Duarte GP. Clin Exp Pharmacol Physiol 2004;31:219.

[20] Sensch O, Vierling W, Brandt W, Reiter M. Planta Med 1993;59(Suppl A):687.

[21] El Tantawy ME, El Sakhawy FS, El Sohly MA, Ross SA. J Essent Oil Res 1999;11:386.

[22] Moncada S, Palmer RMJ, Higgs EA. Pharmacol Rev 1991;43:109.

[23] Furchgott RF, Zawadzki JV. Nature 1980;288:373.

[24] Gurney AM. Pharm Pharmacol 1994;46:242.

[25] Karaki H, Weiss GB. Life Sci 1998;42:111.

[26] Chan W, Yao X, Ko W, Huang Y. Cardiovasc Res 2000;46:180. 